\title{
Giant Hydatid Cyst of the Liver: A Case Report
}

\author{
Mountassir Moujahid $^{1 *}$, Issam Enna-Faa ${ }^{2}$, Mohamed Ghari ${ }^{2}$, Issam Raissouni ${ }^{3}$, Moulay Hassan Tahiri ${ }^{1}$ \\ ${ }^{1}$ Department of General Surgery, 5th Military Hospital, Guelmim, Morocco; ${ }^{2}$ Department of Radiology, 5th Military Hospital, Guel- \\ mim, Morocco; ${ }^{3}$ Department of Reanimation, 5th Military Hospital, Guelmim, Morocco. \\ Email: *m.moujahid@gmx.fr
}

Received November $18^{\text {th }}, 2013$; revised December $10^{\text {th }}, 2013$; accepted December $31^{\text {st }}, 2013$

Copyright (C) 2014 Mountassir Moujahid et al. This is an open access article distributed under the Creative Commons Attribution License, which permits unrestricted use, distribution, and reproduction in any medium, provided the original work is properly cited. In accordance of the Creative Commons Attribution License all Copyrights (C) 2014 are reserved for SCIRP and the owner of the intellectual property Mountassir Moujahid et al. All Copyright (C) 2014 are guarded by law and by SCIRP as a guardian.

\section{ABSTRACT}

It is a cosmopolitan disease due to the embryonic shape of taenia of the dog echinococcosis granulosis. It is the disease which puts a real problem of public health in our country. We report a case of giant hydatid cyst of the liver.

\section{KEYWORDS}

\section{Hydatic Disease; Liver Hydatic; Echinococcosis Granulosis; Diagnostic and Treatment}

\section{Introduction}

Tumor developed in the hepatic parenchyma from the taenia of the dog: the echinococcosis granulosis under its embryonic shape. It constitutes a real problem of the public health; the treatment is essentially surgical by solving the problem of the residual cavity and the biliary fistulas. The prevention is based especially on the disease prevention and the hygienic dietary measures.

We report a case of a giant hydatid cyst occupying all the right liver.

\section{Observation}

A 32-year-old young woman without surgical medical histories, habitant in rural areas, admitted in the service of surgery for an abdominal mass evolving in an apyretic context with preservation of the general state, no notion of vomiting nor disorders of transit, there is no icterus. The clinical examination is without particularity except a tumefaction occupying all the right hypochondria. The abdominal echograph showed an enormous cyst of liquidize density occupying almost all of the right liver without partitions or vegetations cystic corresponding in stade 1 of the classification of Gharbi and Hussein (Figure 1). The abdominal scanner showed a voluminous cyst measuring $24 \times 17 \times 16 \mathrm{~cm}$ and occupying the total-

\footnotetext{
"Corresponding author.
}

ity of the right liver (Figure 2). The blood tests show no anomaly and the hydatic serology was negative. The lung radiography showed an extra height of the right diaphragmatic dome in touch with the hydatid cyst (Figure 3).

The patient was operated the exploration objective an enormous hydatid cyst in the right liver, after protection by abdominal fields soaked with hydrogen peroxide (Figure 4), draining inhalation of the contents of the cyst returned 6 liters of liquid (water of rock) (Figure 5), an extraction of proligeres membranes as well as a resection of the striking dome were realized with padding and drainage by an aspirated drain of the residual cavity (Figures 6 and 7). There was no biliary fistula. The consequences were simple and the patient left the service in sixth days. No sign of second recurrence on a backward movement of two years.

\section{Discussion}

The echinococcosis a cosmopolitan anthropozoonosis, affecting the man and some mammals, connected to the development in the body of the embryonic shape or hydatic of a tape worm of the dog called echinococcosis granulosis.

It is the disease which puts a real problem of public health in our country. The dog constitutes the definitive host. The man is only an accidental intermediate host, who becomes infected either directly in the contact of the 


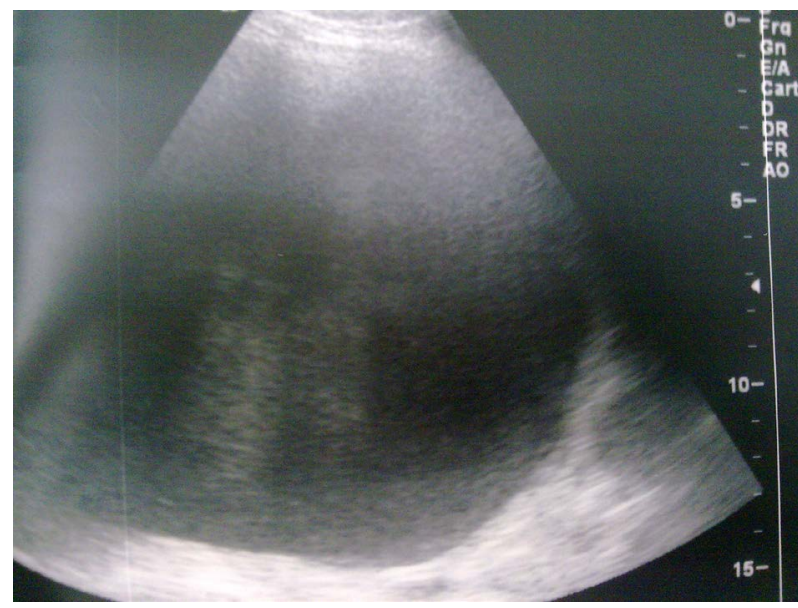

Figure 1. Abdominal echograph showing a voluminous hydatid cyst of the right liver.

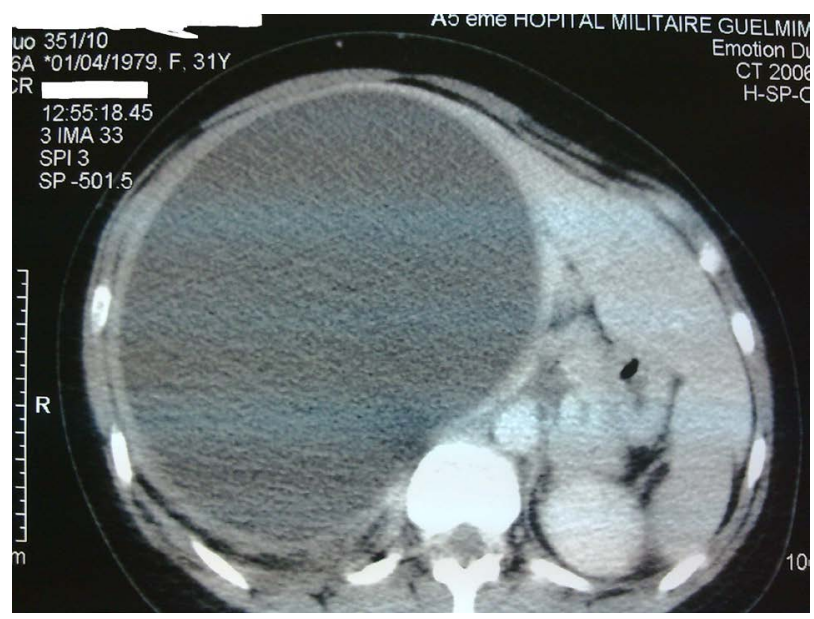

Figure 2. Abdominal scan showing a voluminous hydatid cyst of the right liver.

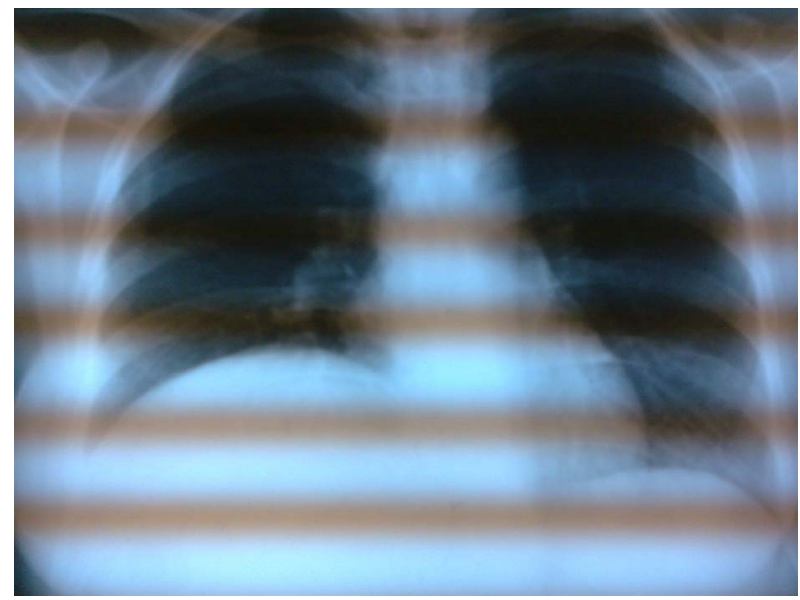

Figure 3. Right lung radiography showing an extra height of the right diaphragmatic dome.

lived as a parasite dog or indirectly by consumption of soiled food [1]. Embryonic eggs, eliminated in the outside

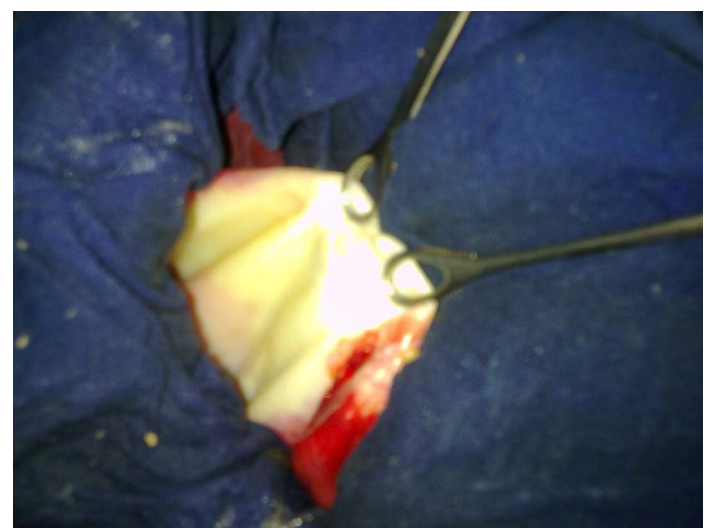

Figure 4. Exposure of the operative field with aspiration of the cyst.

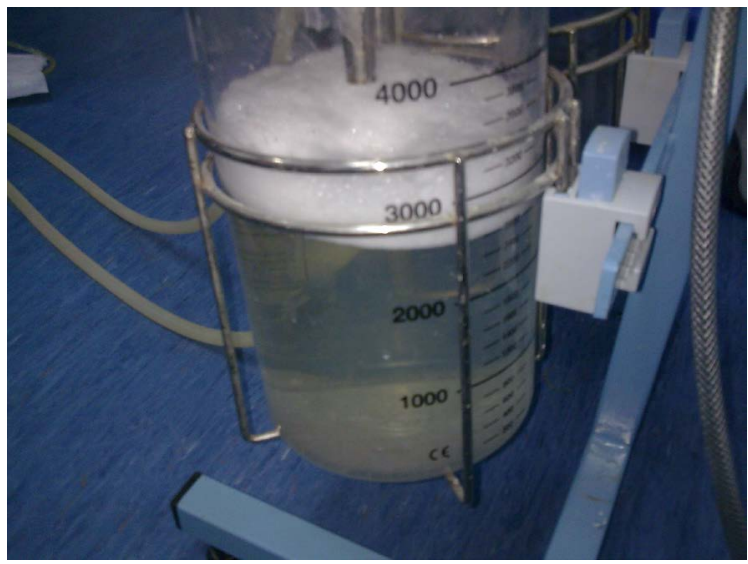

Figure 5. Aspiration of 3litres of clear liquid: water of rock.

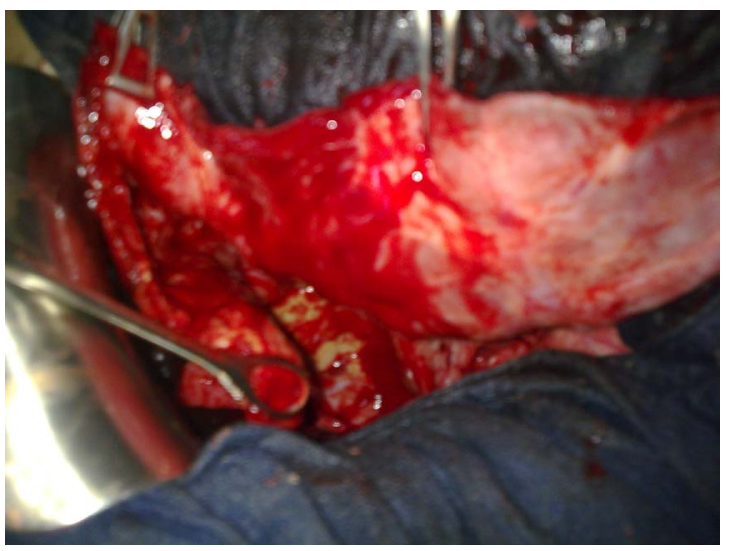

Figure 6. Destruction of the hepatic parenchyma by the hydatid cyst.

environment with the saddles of the dog, are ingested, penetrate into the digestive wall, win by the system carry the liver, sometimes exceed the liver by sus hepatic veins and reach lungs. More rarely, the localization can be made in any point of the body. Of other one unusual localizations were reported in particular in the bone 1a $3 \%$, pleura or peritoneum $4 \mathrm{a} 7 \%$, spleen and kidney 2a 5\%, 


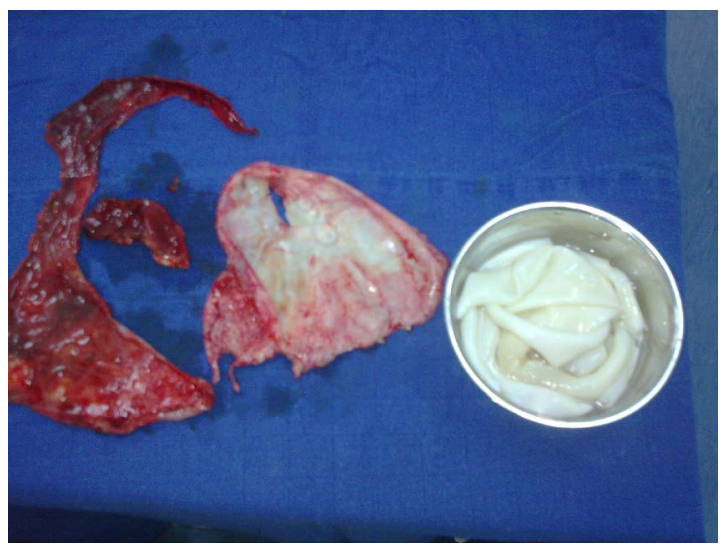

Figure 7. Peri cystectomy with proligere membrane.

brain 1a 5\%, heart $0.5 a$ 2\% [2]. More exceptionally the thyroid, the pancreas, the ovaries, the articulations, the mild parts under coetaneous and muscular. The clinical symptom is variable, often dumb because of the deep localization at the level of the dome. Symptoms are in the late majority of the cases showing itself enough at the stage of complications such the break in the biliary ways or the pleura. The pain of the right hypochondria is the most frequent clinical sign [3]. The fortuitous discovery is especially more and more noted during a balance sheet.

The abdominal echograph which is a harmless, repetitive and little expensive exam, constitutes the method of choice for the diagnosis and the supervision. She allows classifying cysts according to the classification of Hussein and Gharbi [4]:

1) Type I: pure liquid collection

2) Type II: liquid collection in divided into halves wall

3) Type III: liquid collection divided up with girls vesicles

4) Type IV: formation with heterogenic echo structure

5) Type V: formation with calcified wall.

The scan is indicated in case of difficult diagnose ultrasound especially for the typical cysts type IV, as well as for a precise preoperative balance sheet of extension what facilitates the choice of the way at first $[2,4]$.

The magnetic resonance imaging did not demonstrate its superiority in this pathology, if it is not in case of break of the cyst in the biliary ways by practicing a cholangio MRI [5].

The treatment of the hepatic hydatid cyst is essentially surgical allowing to confirm the diagnosis and to insure a complete cure. The hydatid cyst of the liver is in the majority of the cases, a mild hurt. The surgical treatment has to remain the least aggressive [2,6,7]. This surgery presents some difficult especially in the office of the cyst at the level of the dome. The first abdominal way seems more appropriate that the right thoracotomy $[4,8]$. The laparoscopic surgery allowed enriching the therapeutic outfit of the hydatid cyst of the liver [6,7,9]. The draining per cutaneous evacuation with alcoholization is an attractive technique but it is reserved for the small superficial hydatid cyst of the liver [10]. The medical treatment allowed improving the results of the surgical treatment.

\section{Conclusion}

The hydatid cyst is a cosmopolitan affection which puts a real problem of public health in our country. The treatment is so essentially surgical that one must be aggressive enough to decrease the postoperative morbidity, but not be too much to increase the mortality. The best treatment generally rests the individual and collective disease prevention.

\section{REFERENCES}

[1] N. Nadeem, H. Khan, S. Fatimi and M. N. Ahmad, "Giant Multiple Intra-Abdominal Hydatid Cysts,” Journal of Ayub Medical College Abbottabad, Vol. 18, No. 4, 2006, pp. 71-73.

[2] S. Guerid, "Nermin Halkic Giant Liver Cyst," Schweiz Medical Forum, Vol. 4, 2004, p. 178.

[3] M. Daali, R. Hssaida, M. Zoubir, et al., "Moroccan Experience in the Surgical Treatment of Multiple Hydatid Cysts in the Liver," Sante, Vol. 11, No. 3, 2001, pp. 177184.

[4] H. G. Schipper and P. A. Kager, "Diagnosis and Treatment of Hepatic Echinococcosis: An Overview," Scandinavian Journal of Gastroenterology, Vol. 39, No. 241, 2004, pp. 50-55. http://dx.doi.org/10.1080/00855920410011004

[5] O. Ernest, T. Asseiah, I. Fakir, et al., "Cholangio Wirsungography by MRI,” Annals of Surgery, Vol. 51, No. 1, 1997, pp. 111-114.

[6] M. Abbas, A. I. Nafeh, Y. F. Youssef, et al., "Conservative versus Radical Surgery for Treatment of Uncomplicated Hepatic Hydatid Cysts," Journal of the Egyptian Society of Parasitology, Vol. 36, No. 2, 2006, pp. 559576.

[7] F. El Fares, F. Abi, G. Rabeh, et al., "Laparoscopic Surgical Treatment of Hydatid Cyst of the Liver," Maroc Médical, Vol. 22, No. 1, 2000, pp. 21-25.

[8] R. A. Smergo and P. Sebanego, "Treatment Options for Hepatic Cystic Echinococcosis,” International Journal of Infectious Diseases, Vol. 9, No. 2, 2005, pp. 69-76. http://dx.doi.org/10.1016/j.ijid.2004.08.001

[9] G. Kouraklis and T. Dosios, "Surgical Management of a Hydatid Cyst of the Hepatic Dome Ruptured into the Biliary Tree,” International Surgery, Vol. 87, No. 4, 2002, pp. 208-211.

[10] C. Y. Chan, C. H. J. Tan, S. P. Chew and C. H. The, “The Laparoscopic Fenestration of a Simple Hepatic Cyst," Singapore Medical Journal, Vol. 42, No. 6, 2001, pp. 268-270. 